International Journal of Advanced Trends in Computer Science and Engineering

Available Online at http://www.warse.org/IJATCSE/static/pdf/file/ijatcse3091.42020.pdf

https://doi.org/10.30534/ijatcse/2020/3091.42020

\title{
Development of Superconducting Magnetic Levitation (Maglev) Train Prototype Controlled Using Arduino
}

\author{
Hairulazwan Hashim ${ }^{1}$, Muhammad Nur Shafiq Sudin ${ }^{2}$ \\ ${ }^{1}$ Faculty of Engineering Technology, Universiti Tun Hussein Onn Malaysia, 86400 Parit Raja, Batu Pahat, Johor, \\ MALAYSIA. azwan@uthm.edu.my. \\ ${ }^{2}$ Faculty of Engineering Technology, Universiti Tun Hussein Onn Malaysia, 86400 Parit Raja, Batu Pahat, Johor, \\ MALAYSIA.shafiqsudin13@gmail.com.
}

\begin{abstract}
Train transportation has proven to have an effective performance as this type of transportation commonly chosen by the passenger to travel. Passenger can reduce cost, time and increase safety along their journey than road travel. Maglev train is a train that levitates on the magnetic rail or track. The noise pollution and derailment problem produced by the High-Speed Rail train contributed to the development of maglev trains in a developed country like Japan. A prototype of a maglev train that is driverless for educational purposes was developed in this study. Focusing on two main systems, which are Obstacle Detection System that can detect an obstacle to avoid collision to maintain the safety of the passengers and the Blynk Interface System that helps to remotely control from a smartphone. NodeMCU ESP8266 is used as the controller to control the whole systems. The result showed that the train will begin to move when the DC motor speed in PWM is 250. Moreover, the starting of the train can be controlled by the Blynk interface system and the train is able to stop when the IR sensor detects an obstacle in $28 \mathrm{~cm}$ and above ahead of the train.
\end{abstract}

Key words: Blynk, Maglev, NodeMCU ESP8266, train

\section{INTRODUCTION}

The majority of people in the growing country in this world is using the train as transportation to travel, either for a short distance or long-distance destination. Railway technology has long existed with its roots in the $19^{\text {th }}$ century and more than 170 years of history since the opening of an advanced passenger railway line between Liverpool and Manchester [1]. Train transportation has proven to have an effective performance as this type of transportation commonly chosen by the passenger to travel. Passenger can reduce cost, time and increase safety along their journey than road travel. Besides that, the train system can move a large number of passengers at one time even without the integration of smart transport services [2] or intelligent transport system [3].
However, even though the safety precautions have been improvised, there were still a lot of accidents reported for railway trains. Rail accidents bring a huge impact on the country because many passengers involve. The causes of accidents are natural, human errors such as over-speed and wrong signals, mechanical and construction fail and sabotage [4]. The incident such as lack of human errors and mechanical failure can be avoided by maintaining work efficiency, proper schedule maintenance of the train braking systems and control systems.

The usage of steam and diesel engines contributes to a large amount of air and sound pollution to the earth. Sleep disturbance, movement, efficiency and focus, irritation and stress, biological risk factors, cardiovascular diseases and psychiatric disorders include health effects induced by noise [5]. The Japanese introduced a high-speed train travel with the increasing engineering technology, a speed of $210 \mathrm{~km} / \mathrm{h}$ in the rail system's commercial service in October 1964 [6]. Electric trains travel faster because it has a higher speed and produces zero air pollution. With High Speed Rail (HSR), railways are now dominated by a broad variety of activities ranging from signalling and tracking to scheduling and ticket sales [1]. Additionally, the invention of global positioning satellites (GPS) made possible of driverless train and signalling thus reduce human errors and costs.

The electric motor technology enables safe operation at speeds greater than $300 \mathrm{~km} / \mathrm{h}$, without harm caused by human errors. Since, the HSR trains use rail, the derailment problem has occurred when the train speeds up to $300 \mathrm{~km} / \mathrm{h}$. The friction between the wheels and rail also produces a loud noise. For the case of high speed, friction between rail and wheel might lose its grip and will cause a derailment. As a result, the train cannot move faster at their optimum speed. To overcome these problems, the Magnetic Levitation (Maglev) train is introduced. The purpose of this study is to develop the controller for the prototype of a Maglev train for an educational training kit using Arduino Blynk as a controller. 
Hairulazwan Hashim et al., International Journal of Advanced Trends in Computer Science and Engineering, 9(1.4), 2020, $203-207$

\section{MATERIALS AND METHODS}

\subsection{Maglev Train Technology}

Magnetic Levitation (Maglev) or magnetic suspension is a method used to counteract the effects of the gravitational forces. While a conventional train drives forward using friction between wheels and rails, the Maglev train replaces wheels with electromagnet and levitates on the guide, producing electromechanical propulsion force without any contact.

There are two types of Maglev systems named Electro-Magnetic Suspension (EMS) and Electro-Dynamic Suspension (EDS). EMS is a system based on the magnetic attraction force between a guideway and electromagnets. EMS work by continuously maintaining alternating current sent to electromagnets to change the strength of the magnetic fields and allow a stable levitation to occur. The feedback loop will automatically adjust one or more electromagnets to cancel instability [7]. EDS is a system that uses cryogenically cooled superconducting magnets on moving cars, repelled by currents induced in coils embedded on tracks on each side of the train. EDS train has stable levitation, so that regulation of the air gap is unnecessary and very effective for load variability. Hence EDS is highly compliant with high-speed and freight operations.

\subsection{Maglev Development}

In some countries, faster time travels mean shorter time is taken and high satisfaction from a passenger. This is where the idea of using magnetic levitation as a main operating system came to achieve higher speed with higher safety. Maglev is effective when it comes to a long-distance journey with zero pollution and emissions. Since 1969, Germany Engineering, the Transrapid International (TRI)[8] has been studying high-speed rail using electromagnetic levitation devices, naming the TR02 in 1971. TRI maglev system has developed an attractive magnetic force configuration based on a long stator linear synchronous motor with traditional electromagnets. China began the research of maglev technology from the late '80s. The SMT [9] is more favourable because it produces less noise and passengers experience a comfortable ride even at a higher speed.

Development of Maglev in Japan began when the Japanese National Railways (JNR)[10] established the Linear Motor Propulsion Railway System in 1962, two years before the Bullet train started service. In the Yamanashi Maglev Test line, the linear motor system is not exactly the same from a traditional railroad. A superconducting magnet was mounted on two sides of the vehicles, while the levitation, guidance coils, and propulsion coils are located in the guideway opposite the superconducting magnet. Korea Institute of Machinery and Materials (KIMM) started a research and development project for a low-to-medium speed Maglev system [11] which focuses on the Maglev vehicle with electromagnetic suspension (EMS) system and linear induction motor (LIM) propulsion. Table 1 shows the comparison of commercial Maglev trains in terms of the system, rolling stock, maximum speed and commercialization year.

Table 1: Comparison of Maglev Train

\begin{tabular}{|c|c|c|c|c|}
\hline & $\begin{array}{c}\text { Germany } \\
{[\mathbf{6}]}\end{array}$ & $\begin{array}{c}\text { China } \\
\text { [7] }\end{array}$ & $\begin{array}{c}\text { Japan } \\
{[\mathbf{8}]}\end{array}$ & $\begin{array}{c}\text { Korea } \\
{[\mathbf{9}]}\end{array}$ \\
\hline System & EMS & EMS & EDS & EMS \\
\hline Rolling Stock / Car & 5 & 5 & 7 & 2 \\
\hline $\begin{array}{c}\text { Maximum Speed } \\
\text { (km/h) }\end{array}$ & 436 & 432 & 603 & 110 \\
\hline Commercialization & - & 2004 & 2027 & 2013 \\
\hline
\end{tabular}

The Maglev train has many benefits over high speed rail. The first benefit is the removal of wear from wheel and track offering a significant reduction in maintenance costs. As a result, there are no components that would be wearing out. The second advantage, the magnetic levitation, and the guideway will never cause the train to be derailed. The non-contact system prevents it from sliding and slipping in operation. Moreover, the absence of the wheel creates zero friction and removes much noise and friction. The third advantage is that they are less susceptible to temperature. However, since the Maglev train does not have contact between rails and wheels, the traction motors must provide not only propulsion but also braking forces by direct electromagnetic interaction with the rails. Second, the more weight it takes, the more energy it requires to sustain the levitation force, so it is not ideal for freight [12].

\subsection{Project Architecture}

Figure 1 shows the track of the Maglev train and there are two sections named the Blynk Interface (BI) control system and the Obstacle Detection System (OBS). The block diagram of the OBS is shown in Figure 2. It consists of the NodeMCU ESP8266 as a controller interface to the hardware and software. The NodeMCU was installed in the system to control the train. If the infrared (IR) sensor detects any obstacle ahead of the train, it will send the signal to NodeMCU and stop the train to avoid any collision. The LED indicates the power of the electromagnet which turns off when detects any obstacle ahead. Figure 3 illustrates the block diagram for the BI. This system is operated on a smartphone by Blynk apps as the interface to Arduino. The movement of the train is controlled wirelessly by the virtual Start and Stop button in the Blynk application. 


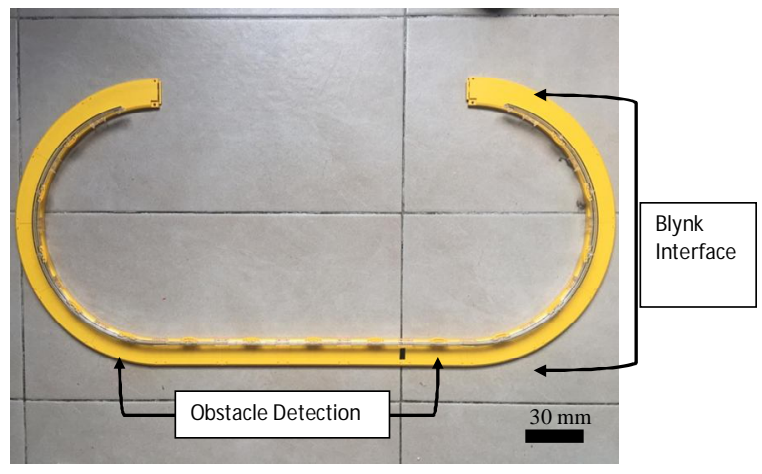

Figure 1: Track of the Maglev Train

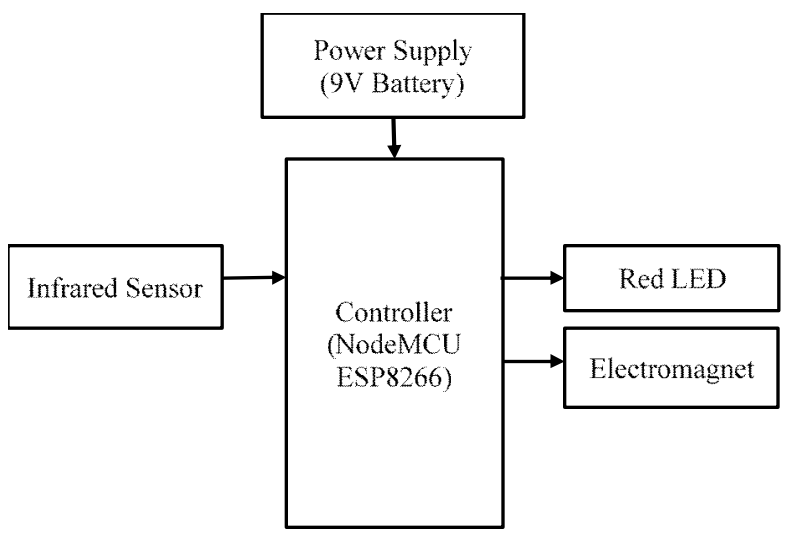

Figure 2: Block Diagram of Obstacle Detection System (OBS)

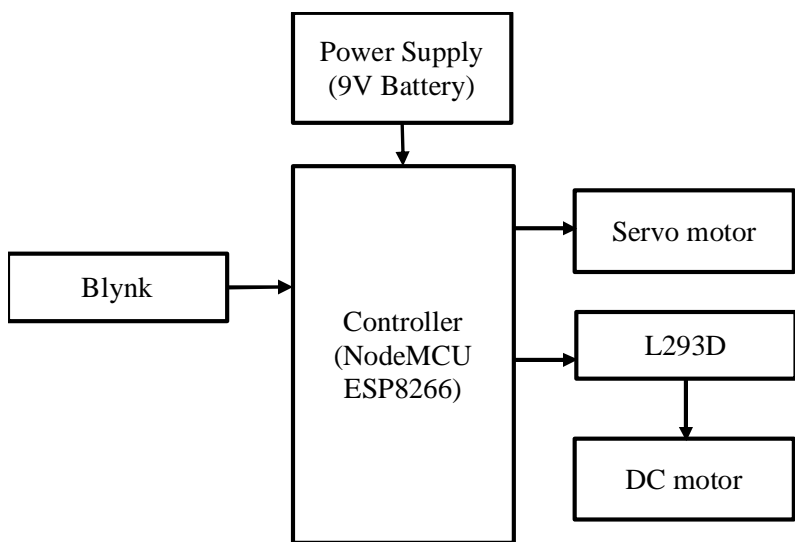

Figure 3: Block diagram for Blynk Interface (BI)

OBS operates when the switch is turned On. Then the electromagnet is energized and the train moves. When the obstacle is detected by the IR sensor, the train will stop for 3 seconds. After 3 seconds, if there are obstacles detected, the train stopped, and the operation is finished. On the other hand, BI operates when the switch is turned On. When the Start button is pressed, the servo motor will rotate to $115^{\circ}$ and the direct current (DC) motor will spin thus move the train. After 3 seconds, the Lift button is pressed in Blynk and the servo motor will return to the initial angle and DC motor stop moving.

\section{RESULTS AND DISCUSSION}

\subsection{Developed Prototype System}

Figure 4 shows the design of the Maglev train with additional components. The prototype is consisting of two systems. The first system is located in the front and middle compartments of the train while the second system is located in the back of the train. The system uses NodeMCU ESP8266 as the processing unit or the brain of the project.

The speed of the DC motor plays important roles to ensure the starting of the train. In comparison, the motor speed was set by the PWM signal which set at 50,150 and 250. The train only moves when the speed of the motor was set at 250 (PWM). Figure 5(a) illustrates the initial position of the train. When the Start button is pressed, the DC rotates and moves the train in the track. When the train reaches the End position as illustrates in Figure 5(b), the DC motor stops rotating, and the Servo motor returns to the initial angle. Then, the electromagnet was energized and hence control the movement of the train.

As the train starts to move, the IR sensor is used to detect obstacles for the ODS. The track is $\mathrm{C}$ shaped because the straight track is combined to get the results for the obstacle safe distance. The sensitivity of the IR sensor towards obstacles was measured at various distances ranged between 7 and $35 \mathrm{~cm}$. Table 2 shows the results of the sensitivity of the IR sensor for the obstacle detection experiment. The distance was compared at 7, 14, 21, 28 and $35 \mathrm{~cm}$. As a result, $28 \mathrm{~cm}$ and above is the safest obstacle distance of this prototype. Figure 6 shows the Blynk application interface when (a) there are no obstacles and (b) there are obstacles detected. This Maglev train took a long time because it is levitated and inertia from the load prevents it to stop immediately on site.
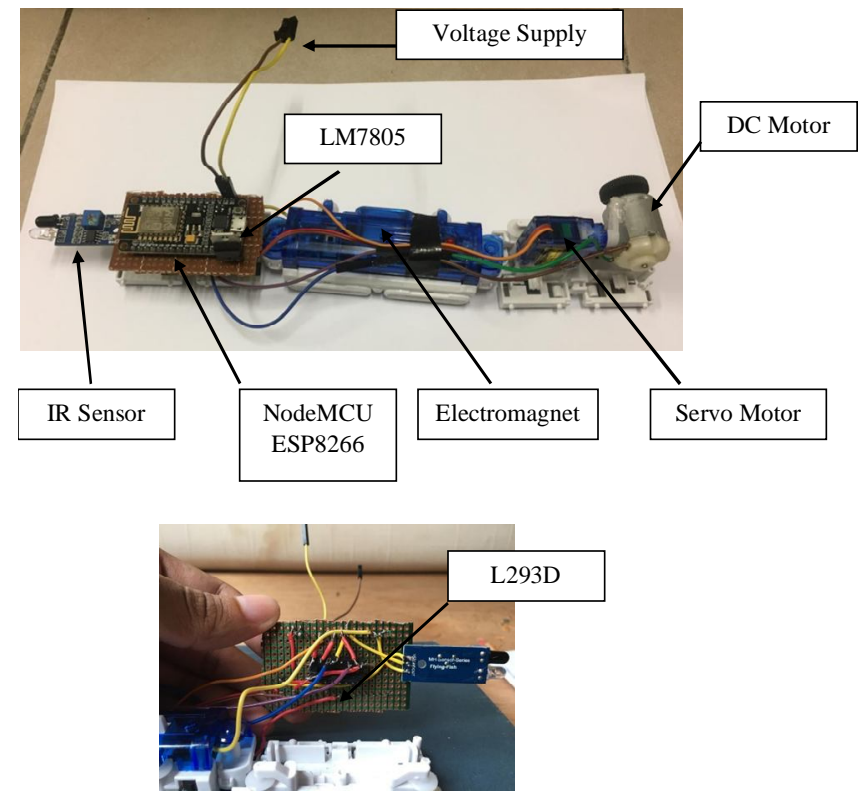

Figure 4: Prototype of Magnetic Levitation Train 


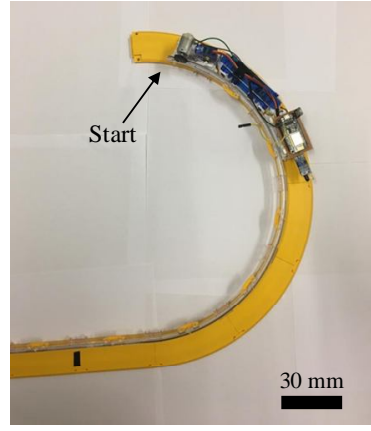

(a)

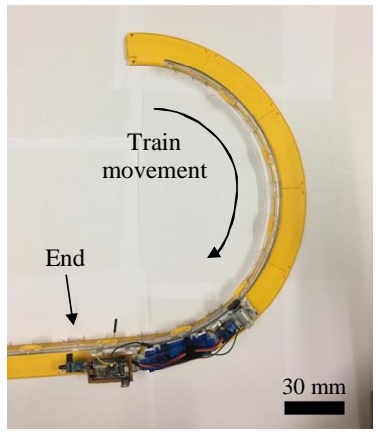

(b)
Figure 5: Blynk Interface (a) Start (b) End

Table 2: Results for Obstacle Detection System

\begin{tabular}{|c|c|}
\hline Distance $(\mathbf{c m})$ & Function \\
\hline 7 & Train crash \\
\hline 14 & Train crash \\
\hline 21 & Train crash \\
\hline 28 & Train safe \\
\hline 35 & Train safe \\
\hline
\end{tabular}

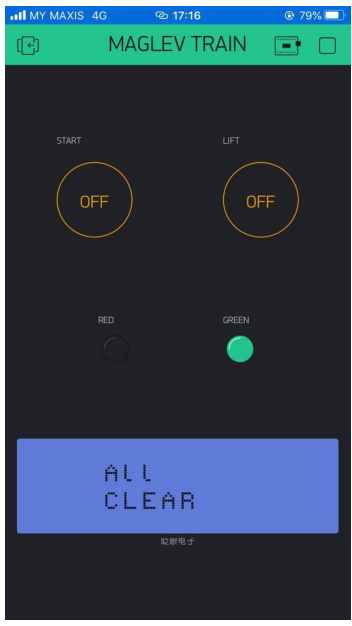

(a)

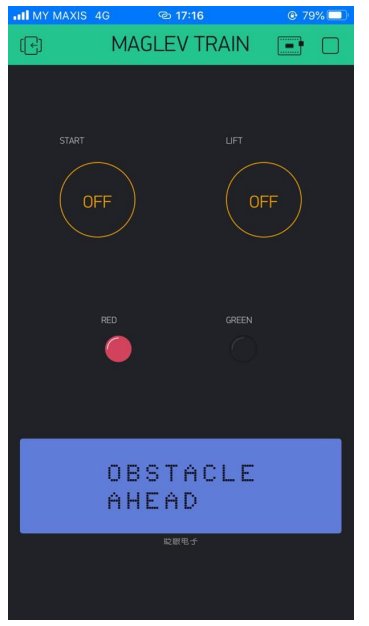

(b)
Figure 6: Blynk Interface (a) No Obstacles (b) Obstacle Detected

Table 3 shows the comparison of levitation height between the original train and prototype train. The levitation height of the prototype trains a bit lower due to the additional components on the train. Therefore, the additional weight on the train decreases the levitation height between track and train as illustrates in Figure 7.

Table 3: Levitation Height of Prototype Train

\begin{tabular}{|c|c|c|c|}
\hline Condition & $\begin{array}{c}\text { Front Side } \\
(\mathbf{m m})\end{array}$ & $\begin{array}{c}\text { Front Side } \\
(\mathbf{m m})\end{array}$ & $\begin{array}{c}\text { Front Side } \\
(\mathbf{m m})\end{array}$ \\
\hline Original & 4 & 4 & 4 \\
\hline $\begin{array}{c}\text { Proposed } \\
\text { levitation } \\
\text { (straight) }\end{array}$ & 2 & 3 & 2 \\
\hline $\begin{array}{c}\text { Proposed } \\
\text { levitation (curve) }\end{array}$ & 0 & 1 & 0 \\
\hline
\end{tabular}

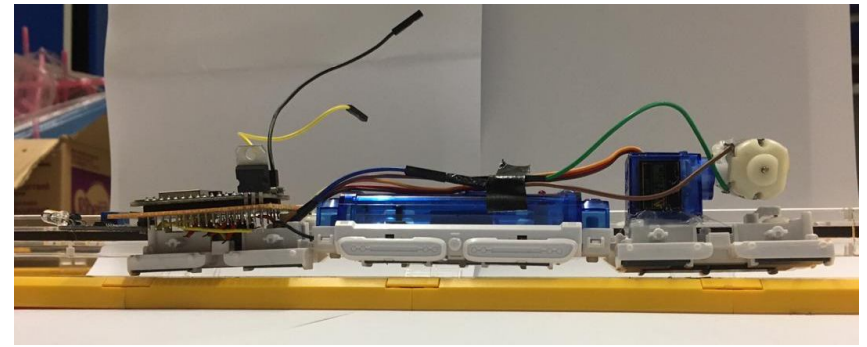

Figure 7: Evaluation of Levitation Height

\section{CONCLUSION}

The prototype of a Maglev train controlled by using Arduino has been successfully developed and validated. The train was able to move and detect obstacles as far as $28 \mathrm{~cm}$ distance and stops at a safe distance. However, a few improvements can be implemented to improve this prototype. For example, the magnet at the train should be stronger so it can levitate higher and can support additional components. Additionally, the train has to be upgraded so it can move across the track forward and backward. Therefore, this issue will be taken into consideration in the future to follow EMS, EDS or Inductrack system that has already established globally. This prototype allows students to learn the basic understanding of the Maglev train as prior to the real commercial train.

\section{ACKNOWLEDGEMENT}

This work was supported by the UTHM TIER-1 research grant (H113).

\section{REFERENCES}

1. R. A. Smith. Railway technology - The last 50 years and future prospects, Japan Railway Transportation Rev., vol. 27, pp. 16-24, 2001.

2. R. C. Veena, L. Dayannand, S. H. Brahmananda, D. S. Sahana and B. M. Mala. A cooperative vehicle intelligence for smart transport services, International Journal of Advanced Trends in Computer Science and Engineering, 9 (2), pp. 2187-2195, 2020. https://doi.org/10.30534/ijatcse/2020/195922020

3. J. Larioui and A. E. Byed. Towards a semantic layer design for an advanced intelligent multimodal transportation system, International Journal of Advanced Trends in Computer Science and Engineering, 9 (2), pp. 2471-2478, 2020.

https://doi.org/10.30534/ijatcse/2020/236922020

4. D. J. R. Gaur. Investigation of railway accidents, Indian Police J., pp. 79-82, 2011.

5. L. den Boer and A. Schroten. Traffic noise reduction in Europe, CE Delft, August, p. 70, 2007.

6. L. Zhou and Z. Shen. Progress in high-speed train technology around the world, J. Mod. Transp., vol. 19, no. 1, pp. 1-6, 2013. 
7. R. M. Goodall. Dynamics and control requirements for EMS Maglev suspensions, Proc. $18^{\text {th }}$ Int. Conf. Magn. Levitated Syst. Linear Drives, pp. 26-28, 2004.

8. Aviva Brecher, Daniel R. Disk, David Fugate, William Jacobs, Amishi Joshi, Arnold Kupferman, Ronald Mauri, P. V. Electromagnetic Field Characteristics of the Transrapid TR08 Maglev System. US Department of Transportation Research and Special Programs Administration, pp. 3-9, 2002.

9. Y. Luguang. Progress of the Maglev transportation in China, IEEE Trans. Appl. Supercond., vol. 16, no. 2, pp. 1138-1141, 2006.

10. M. Ono, S. Koga, and H. Ohtsuki. Japan's superconducting Maglev train, IEEE Instrum. Meas. Mag., vol. 5, no. 1, pp. 9-15, 2002. https://doi.org/10.1109/5289.988732

11. B. Shin, W. Kim, D. Park, J. Beak, and H. Kang. Progress of Urban Maglev Program in Korea, World Congr. Rail Res., pp. 1-9, 2011.

12. V. R. Vuchic and J. M. Casello. An evaluation of Maglev technology and its comparison with high speed rail, Transp. Q., vol. 56, no. 2, pp. 33-49, 2002. 